\title{
Restoration of metabolic inflammation-related ghrelin resistance by weight loss
}

\author{
Farhana Naznin', Koji Toshinai1,2, T M Zaved Waise1, Tadashi Okada', Hideyuki Sakoda' and Masamitsu Nakazato1,3 \\ 'Division of Neurology, Respirology, Endocrinology and Metabolism, Department of Internal Medicine, Faculty of Medicine, University of Miyazaki, \\ Miyazaki, Japan \\ 2Department of Sports and Fitness, Faculty of Wellness, Shigakkan University, Obu, Japan \\ ${ }^{3}$ Agency for Medical Research and Development-Core Research for Evolutional Medical Science and Technology (AMED-CREST), Japan Agency for \\ Medical Research and Development, Tokyo, Japan
}

Correspondence should be addressed to M Nakazato: nakazato@med.miyazaki-u.ac.jp

\begin{abstract}
High-fat diet (HFD)-induced metabolic inflammation in the central and peripheral organs contributes to the pathogenesis of obesity. Long-term HFD blunts signaling by ghrelin, a gastric-derived orexigenic peptide, in the vagal afferent nerve via a mechanism involving in situ activation of inflammation. This study was undertaken to investigate whether ghrelin resistance is associated with progressive development of metabolic inflammation. In mice, ghrelin's orexigenic activity was abolished 2-4 weeks after the commencement of HFD ( $60 \%$ of energy from fat), consistent with the timing of accumulation and activation of macrophages and microglia in the nodose ganglion and hypothalamus. Calorie-restricted weight loss after 12-week HFD feeding restored ghrelin responsiveness and alleviated the upregulation of macrophage/microglia activation markers and inflammatory cytokines. HSP72, a chaperone protein, was upregulated in the hypothalamus of HFD-fed mice, potentially contributing to prevention of irreversible neuron damage. These results demonstrate that ghrelin resistance is reversible following reversal of the HFD-induced inflammation and obesity phenotypes.
\end{abstract}

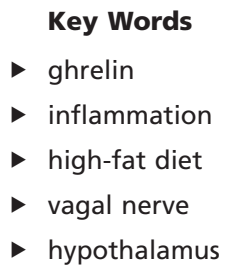

Journal of Molecular Endocrinology (2018) 60, 109-118

\section{Introduction}

Obesity is a long-term disturbance of energy metabolism in which energy intake exceeds energy expenditure over a prolonged period (Moehlecke et al. 2016). The control of food intake and body weight involves central nervous system integration of information from the peripheral nervous system and humoral signals from the gastrointestinal tract (Morton et al. 2006, Begg \& Woods 2013). Vagal afferents that innervate digestive organs transmit sensory information from their endings to the nucleus of the tractus solitarius (NTS) in the medulla oblongata, terminating in distinct hypothalamic nuclei involved in feeding and energy homeostasis. The vagus afferent nerve is a pseudounipolar neuron whose cell body is located in the nodose ganglion, making one projection to the NTS and the other to peripheral organs. Vagal afferent neurons express receptors for gut peptides such as ghrelin, cholecystokinin and glucagon-like peptide 1 that regulate feeding and energy homeostasis (Zarbin et al. 1981, Burdyga et al. 2006, Cummings \& Overduin 2007).

Ghrelin, a peptide primarily produced in the stomach, stimulates feeding (Tschöp et al. 2000, Nakazato et al. 2001). The growth hormone secretagogue receptor (GHSR), also known as the ghrelin receptor, is synthesized in vagal afferent neurons and transported to the stomach by axonal 
transport (Date et al. 2002). Electrophysiological studies indicate that ghrelin hyperpolarizes nodose ganglion neurons by activating $\mathrm{K}_{\mathrm{ATP}}$ conductance (Grabauskas et al. 2015), thereby attenuating electrical activity of the vagal afferent (Date et al. 2002). This ghrelin signal is sent to the NTS and relayed via the noradrenergic pathway to hypothalamic neurons expressing the orexigenic neuropeptides agouti-related peptide (AgRP) and neuropeptide Y (NPY) (Date et al. 2006). GHSR, a G-proteincoupled receptor, activates the intracellular $\mathrm{Ca}^{2+}$ signaling and AMP-activated protein kinase (AMPK) signaling pathways (Kohno et al. 2003, Hardie 2004). Previous studies showed that neither central nor peripheral ghrelin administration induced feeding in diet-induced obese (DIO) mice fed a high-fat diet (HFD, 60\% of energy from fat) for 12 or 16 weeks (Perreault et al. 2004, Briggs et al. 2010, Gardiner et al. 2010, Naznin et al. 2015). Another study demonstrated that ghrelin resistance developed 3 weeks after the start of HFD feeding (in that case, 23.5\% energy from fat) (Briggs et al. 2014). In addition, we showed that ghrelin's effects on energy expenditure, suppression of vagus afferent electrical activity and neuronal activation in the hypothalamic arcuate nucleus were abolished in 12-week HFD-fed mice (Naznin et al. 2015). All of these DIO experiments used C57BL/6J mice, which develop severe obesity, hyperglycemia and insulin resistance (Reed et al. 2007). Consumption of HFD induces immune cellmediated tissue inflammation in the gut, adipose tissue, liver, skeletal muscle and hypothalamus (De Souza et al. 2005, Schenk et al. 2008, Thaler et al. 2012, Hotamisligil 2017), which causes macrophage-associated pathological alterations and insulin resistance. We confirmed that HFD caused accumulation and activation of macrophages and microglia in the nodose ganglion and hypothalamus of mice (Naznin et al. 2015). These inflammatory responses resulted in the reduction of Ghsr expression in these neuronal tissues, causing impaired transmission of gastricderived ghrelin signals to the hypothalamus (Naznin et al . 2015). Ghrelin resistance under HFD is thought to be caused by dysregulation of ghrelin signaling via the vagal afferent. Ghrelin resistance is the consequence of several factors in addition to dysregulation of the ghrelin signaling via vagal nerve. Peripheral ghrelin reaches the hypothalamus by passive diffusion through the fenestrated capillaries of the median eminence, which project to the ventromedial part of the ARC and ultimately target NPY/AgRP neurons to induce a metabolic response (Schaeffer et al. 2013).

In this study, we sought to determine when ghrelin resistance develops during HFD exposure of mice and to investigate whether the onset of ghrelin resistance is linked to inflammation in the nodose ganglion and hypothalamus. Subsequently, we investigated whether calorie-restricted weight loss could reverse inflammation in these neuronal tissues in order to restore ghrelin sensitivity.

\section{Materials and methods}

\section{Animals and dietary protocols}

Male C57BL/6J mice (6-week-old male, 20-21g, Charles River Laboratories) were maintained in individual cages under controlled temperature $\left(21-23^{\circ} \mathrm{C}\right)$ and light (light on: 08:00-20:00) conditions. All animal experiments were approved by the Animal Care and Use Committee of University of Miyazaki.

\section{Study 1: time course of ghrelin resistance}

Mice were maintained on either chow diet (CD) (12.3\% fat, $59.2 \%$ carbohydrate, $28.5 \%$ protein, $14.2 \mathrm{~kJ} / \mathrm{g}$; CLEA Rodent Diet CE-2, CLEA Japan, Tokyo, Japan) or HFD (60\% fat, 20\% carbohydrate, $20 \%$ protein, $21.9 \mathrm{~kJ} / \mathrm{g}$; no. D12492; Research Diets, New Brunswick, NJ, USA), with free access to food, for 12 weeks. Respective percentages of saturated fatty acid, monounsaturated fatty acid and polyunsaturated fatty acid in the HFD were 32,36 and $32 \%$. Body weight and 24-h food intake were measured weekly. 'Pre' indicates the period before starting the HFD (Fig. 1).

\section{Study 2: caloric restriction}

Mice were assigned to one of three diet groups: HFD for 16 weeks (HFD group); HFD for 12 weeks followed by a switch to CD for 2 weeks and then calorie restriction $(60 \%$ ad libitum) for 2 weeks until their body weights reached those of age-matched CD-fed controls (HFD-CD/CR group); and standard laboratory chow for 16 weeks (CD group). .

\section{Food intake experiments}

Mice fed CD or HFD ( $n=6$ per group) were transferred to single cages and maintained for 1 week. They were acclimatized by subcutaneous (s.c.) injections of saline once daily for 3 days before the feeding experiment. Ghrelin (60 nmol/kg BW; Peptide Institute, Osaka, Japan) was administered subcutaneously (s.c.), and 2-h food intake was measured.

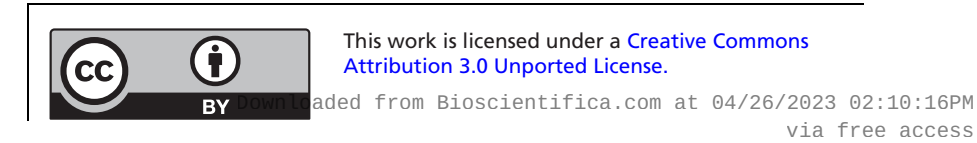



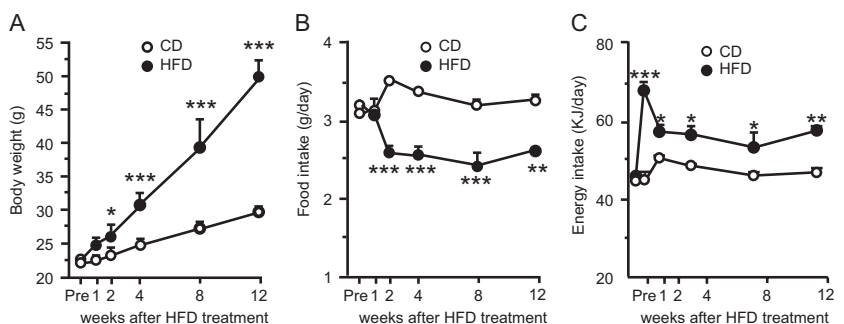

D

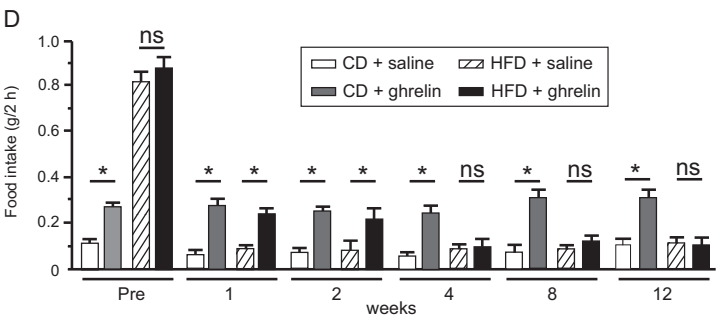

E

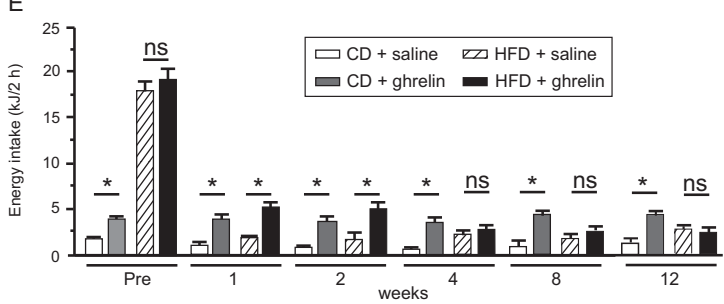

Figure 1

Changes in body weight (A), food intake (B) and energy intake (C) of mice fed CD or HFD for 12 weeks. Effects of HFD on ghrelin-induced food intake (D) and energy intake (E) in 1-, 2-, 4-, 8-, or 12-week CD- or HFD-fed mice. Values are means \pm s.E.M. $n=6-8 .{ }^{*} P<0.05, * * P<0.01$, $* * * P<0.001$.

\section{Energy expenditure}

Mice fed CD or HFD ( $n=4-12$ per group) were housed in a metabolic chamber (Shinfactory, Fukuoka, Japan) for 1 week. They received s.c. injection of ghrelin $(60 \mathrm{nmol} /$ $\mathrm{kg} \mathrm{BW}$ ) or saline at 10:00 and were then returned to the chamber. Energy expenditure was measured for $2 \mathrm{~h}$ in an Oxymax (Columbus Instruments, Columbus, OH, USA). Mice were deprived of food during the measurement.

\section{Measurement of blood parameters}

Mice were fasted from 09:00 to 14:00 before blood collection by tail prick. Blood glucose was measured using a glucometer (Terumo, Tokyo, Japan), and plasma insulin was measured using a mouse insulin EIA kit (Morinaga Institute of Biological Science, Yokohama, Japan). For plasma ghrelin measurements, mice were anesthetized deeply with sodium pentobarbital (Abbott Laboratories), and blood samples were collected by cardiac puncture. Plasma ghrelin was measured using the active ghrelin ELISA Kit (Mitsubishi Chemical Medience, Tokyo, Japan; intra- and inter-assay precision coefficient of variation $<10 \%$, assay range $2.5-160 \mathrm{fmol} / \mathrm{mL}$ ). All samples were measured in duplicate.

\section{Real-time polymerase chain reaction ( $R T-P C R$ )}

The nodose ganglion and hypothalamus were quickly removed from anesthetized CD- or HFD-fed mice. The tissue was stored in RNAlater (Life Technologies) at $-80^{\circ} \mathrm{C}$. For RNA extraction, samples were placed in tubes containing autoclaved glass beads (425-600 $\mu \mathrm{m})$ (SigmaAldrich) and vortexed for $6 \mathrm{~min}$ on a TissueLyser (Qiagen). Total RNA was extracted using the RiboPure kit (Ambion). RT-PCR was conducted on a Thermal Cycler Dice RealTime System II (Takara Bio) using SYBR Premix Ex Taq $(2 \times)$ (Takara Bio). Primer sets for RT-PCR are shown in Table 1. mRNA levels for each gene were normalized against the level of Tbp mRNA in the same sample, used as an internal control.

\section{Immunohistochemistry}

Nodose ganglia and whole brains ( $n=4-5$ per group) were immersed in $4 \%$ paraformaldehyde/phosphate buffer for $24 \mathrm{~h}$ at $4^{\circ} \mathrm{C}$, incubated for $24 \mathrm{~h}$ in $\mathrm{PB}$ containing $20 \%$ sucrose, quickly frozen on dry ice and cut into $8-\mu \mathrm{m}$ slices using a cryostat at $-20^{\circ} \mathrm{C}$. Sections were blocked for

Table 1 Primer sequences for genes used in the real-time PCR analysis.

\begin{tabular}{l} 
Gene \\
\hline Ghsr \\
TIr4 \\
Iba1 \\
II6 \\
Thfo \\
Ap2a \\
Bhlhe22 \\
Nrebp \\
Tbp
\end{tabular}

\begin{tabular}{|c|c|}
\hline \multicolumn{2}{|l|}{ Forward primer } \\
\hline ATCACСТCTGG & GCTG \\
\hline GGAAGTTCACA & ATGAC \\
\hline AGCTGCCTGTC & GCATC \\
\hline CCACTTCACAA & ¡GCTTA \\
\hline TATGGCCCAGA & \\
\hline ACCCTCGTGTG & AGA \\
\hline CTGACAATTGG & ATGAAAG \\
\hline TGACAGTGGCC & $\mathrm{TTC}$ \\
\hline САТТСТСАAАC & ACTGCAC \\
\hline
\end{tabular}

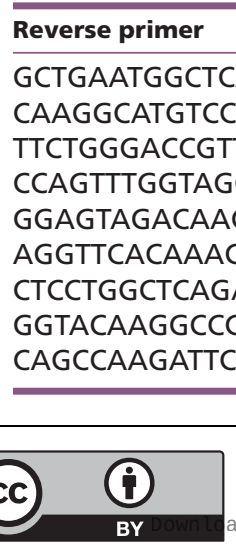

Reverse primer

GCTGAATGGCTCATTGTAGTCCTG

CAAGGCATGTCCAGAAATGAGA

TICTGGGACCGTTCTCACACTTC

AGGTTCACAAACGCGACAGA

CTCCTGGCTCAGAATCAAGATG

GGTACAAGGCCCATTGCTTGA

CAGCCAAGATTCACGGTAGATACAA 
$5 \mathrm{~min}$ in protein-block serum-free solution (Dako), and then incubated overnight at $4^{\circ} \mathrm{C}$ with rabbit anti-Iba1 (1:10,000; Wako Pure Chemicals), rat anti-CD86 (1:100; Abcam), mouse anti-HSP72 (1:50; Enzo Life Sciences, New York, NY, USA) or mouse anti-NeuN (1:200; Millipore, Chemicon International). Immunofluorescence was performed with Alexa Fluor 488-labeled anti-rabbit secondary antibody or Alexa Fluor 594-labeled anti-mouse secondary antibody (both 1:400; Invitrogen). Images were captured on an OLYMPUS AX-7 fluorescence microscope (Olympus). Cells immunoreactive for Iba1, CD86 or HSP72 in the nodose ganglion and hypothalamus of three mice were counted manually in three to five sections per mouse using the cellSens imaging software (Olympus). Quantitation was performed in a blinded fashion.

\section{Statistical analysis}

Statistical analyses were performed by one- or two-way ANOVA followed by a Bonferroni's post-test for multiple comparisons, as appropriate. When two mean values were compared, analysis was performed by Mann-Whitney, Wilcoxon or unpaired $t$-test. All data are expressed as means \pm S.E.M. $P<0.05$ was considered to be statistically significant.

\section{Results}

\section{Effects of HFD on body weight, food intake and ghrelin responses}

Body weights of mice on HFD were significantly higher than those of CD-fed mice 2 weeks after the initiation of HFD feeding (Fig. 1A). Average food intake of HFDfed mice was lower than that of CD-fed mice from 2 to 12 weeks (Fig. 1B), although the energy intake of HFDfed mice was greater during this period (Fig. 1C). Ghrelin administration significantly increased food intake in both 1- and 2-week HFD-fed mice, but not in 4-, 8- or 12-week HFD-fed mice (Fig. 1D and E). Ghrelin administration decreased energy expenditure in both 2- and 4-week CD-fed mice and 2-week HFD-fed mice, but not in 4-week HFD-fed mice (Fig. 2A, B, C and D).

\section{mRNA expression of Ghsr, inflammatory genes and transcriptional factors}

Ghsr mRNA levels in both the nodose ganglion and hypothalamus did not differ significantly between CD-fed and HFD-fed mice at 2 weeks, but at 4 weeks

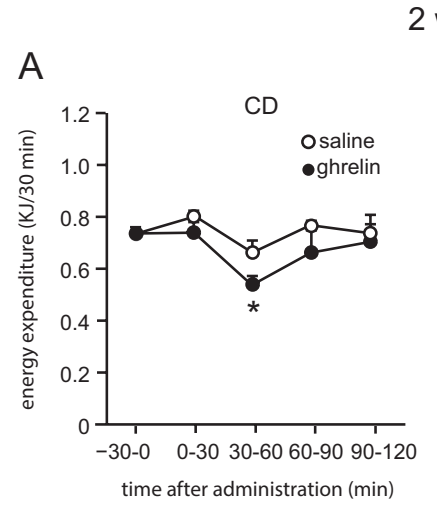

2 weeks

B

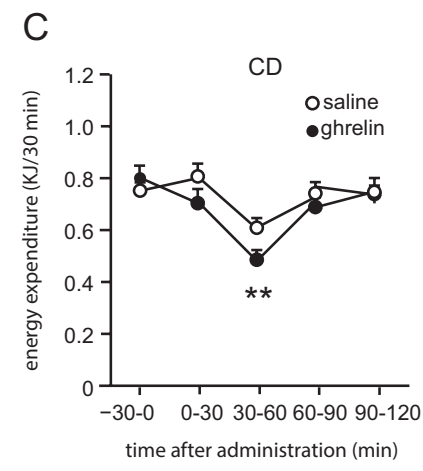

4 weeks

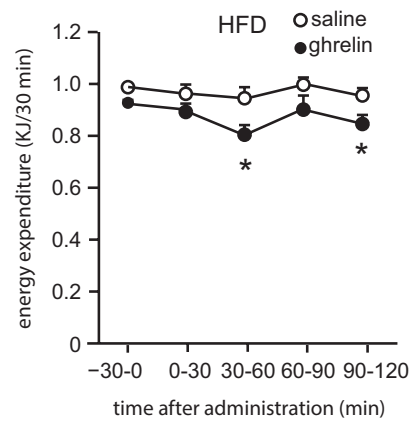

D

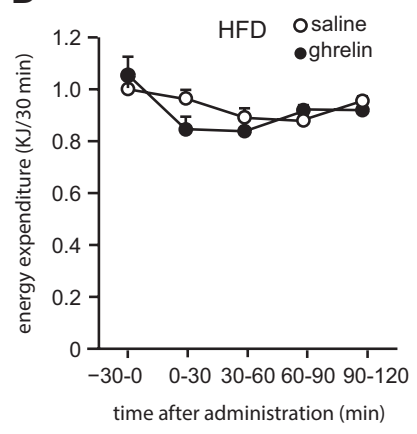

Figure 2

Effect of ghrelin on energy expenditure in DIO mice. Energy expenditure in 2-week CD- (A) or HFD-fed mice (B), and 4-week CD- (C) or HFD-fed mice (D) receiving ghrelin. Values are means \pm S.E.M. $n=4-12 .{ }^{*} P<0.05$, $* * P<0.01, * * * P<0.001$.

were significantly lower in HFD-fed mice (Fig. 3A and B). Tlr4 expression in the nodose ganglion did not differ significantly between CD- and HFD-fed mice at 2 weeks, but was significantly higher in HFD-fed mice at 4 weeks (Fig. 3C). Two-week HFD feeding did not modulate the expression of any of the genes investigated in the nodose ganglion or hypothalamus, in comparison with 2-week CD feeding, whereas 4-week HFD feeding significantly upregulated the Iba1, Il 6 and Tnfo mRNAs in comparison with 4-week CD feeding (Fig. 3D and E). Expression of Ap2a, Bhlhe22 and Nrebp, which encode transcription factors of $G h s r$, in the nodose ganglion and hypothalamus did not differ significantly between the CD and HFD groups at 12 weeks (Fig. 4).

\section{Effect of HFD on immunohistochemical markers of inflammation}

The average number of macrophages stained with antiIba1 antibody in the nodose ganglion (Fig. 5A, B, C, D 
A
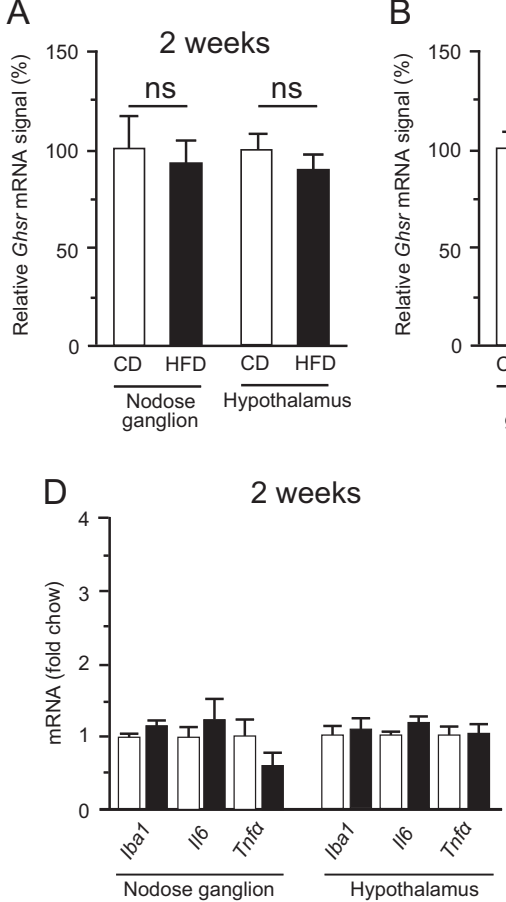

$B$

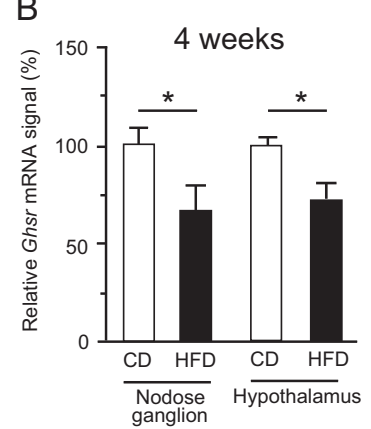

C

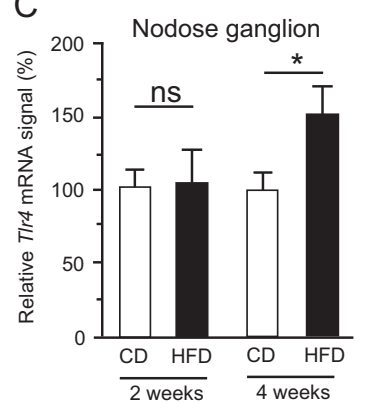

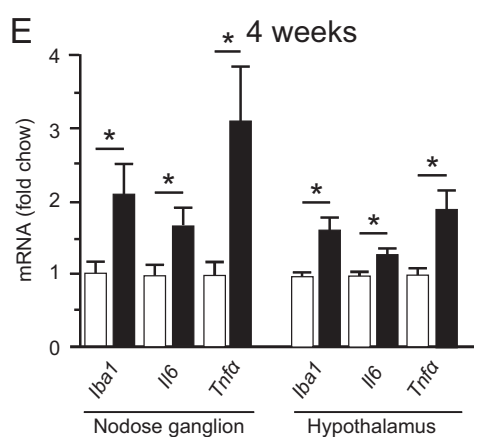

Figure 3

Ghsr mRNA expression in the nodose ganglion (A) and hypothalamus (B) of mice fed CD or HFD for 2 (A) or 4 (B) weeks. mRNA levels of TIr4 (C) in the nodose ganglion of 2- or 4-week CD- or HFD-fed mice. mRNA levels of $I b a 1, I I-6$, and Tnf $\alpha$ in the nodose ganglion and hypothalamus of 2- (D) or 4- (E) week CD- or HFD-fed mice. mRNA levels were normalized against the level of Tbp mRNA (a housekeeping gene) in the same sample, and the normalized values are presented as fold change relative to $C D$. Values are means \pm S.E.M. $n=8-10 .{ }^{*} P<0.05$ vs $C D$. and E) and hypothalamus (Fig. 5F, G, H, I and J) was significantly higher in HFD-fed mice than that in CD-fed mice at 4 weeks, whereas no difference was observed between these two groups at 2 weeks. The expression level of the M1 macrophage marker CD86 in the nodose ganglion was significantly higher in HFD-fed mice than in CD-fed mice at 4 weeks, but no difference between groups was apparent at 2 weeks (Fig. 5K, L, M and N). Macrophages immunoreactive for CD86 in the HFD group were larger and were morphologically rounded and more ramified, than those in the CD group (Fig. 5M). The average number of HSP72-positive cells in the hypothalamus was significantly greater in the HFD group than that in the CD group after 4 weeks of HFD feeding (Fig. $5 \mathrm{O}$ and P).

\section{Effects of caloric restriction on ghrelin sensitivity and inflammation}

The difference in body weight between the $\mathrm{CD}$ and HFD-CD/CR groups became insignificant at the end of 4-week caloric restriction (Fig. 6B). In the HFD-CD/ CR group, epididymal fat weight, fasting blood glucose and plasma insulin and ghrelin returned to normal levels (Fig. 6C, D, E and F). Ghrelin administration significantly stimulated food intake in the HFD-CD/ CR group (Fig. 6G). The Ghsr mRNA level in the nodose ganglion was significantly lower in 16-week HFD mice than that in CD-fed mice, whereas the level in the HFD-CR group did not differ from that in the CD group

\begin{tabular}{|lr}
\hline $\begin{array}{l}\text { http://jme.endocrinology-journals.org } \\
\text { https://doi.org/10.1530/JME-17-0192 }\end{array}$ & ○ 2018 The authors \\
& Published by Bioscientifica Ltd. \\
Printed in Great Britain
\end{tabular}

(Fig. 6H). Iba1, Il6 and Tnf $\alpha$ mRNAs in both the nodose ganglion and hypothalamus of the HFD-CD/CR group were not upregulated relative to the CD group (Fig. 6I).

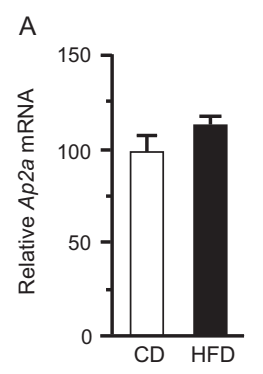

Nodose ganglion
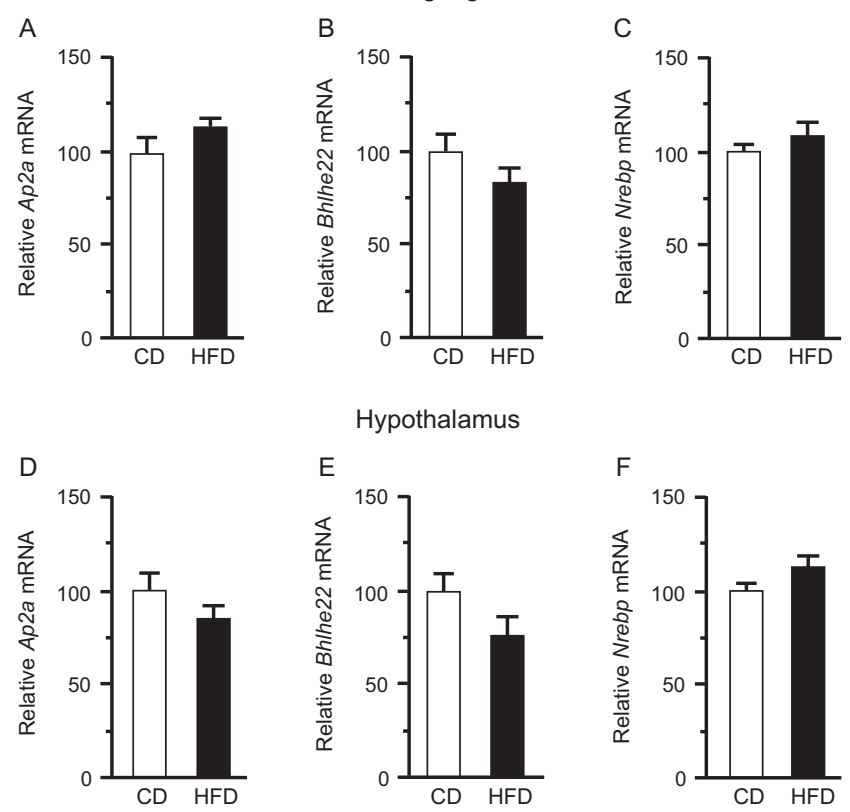

Hypothalamus
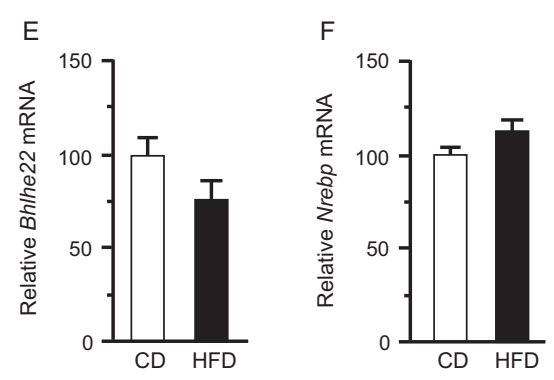

Figure 4

mRNA levels of Ap2a, Bhlhe22, and Nrebp in the nodose ganglion (A, B and $C$ ) and hypothalamus (D, E and F) of CD- or HFD-fed mice at 12 weeks. mRNA levels were normalized against the level of Tbp mRNA in the same sample. $n=9-14$. Values are means \pm S.E.M. 

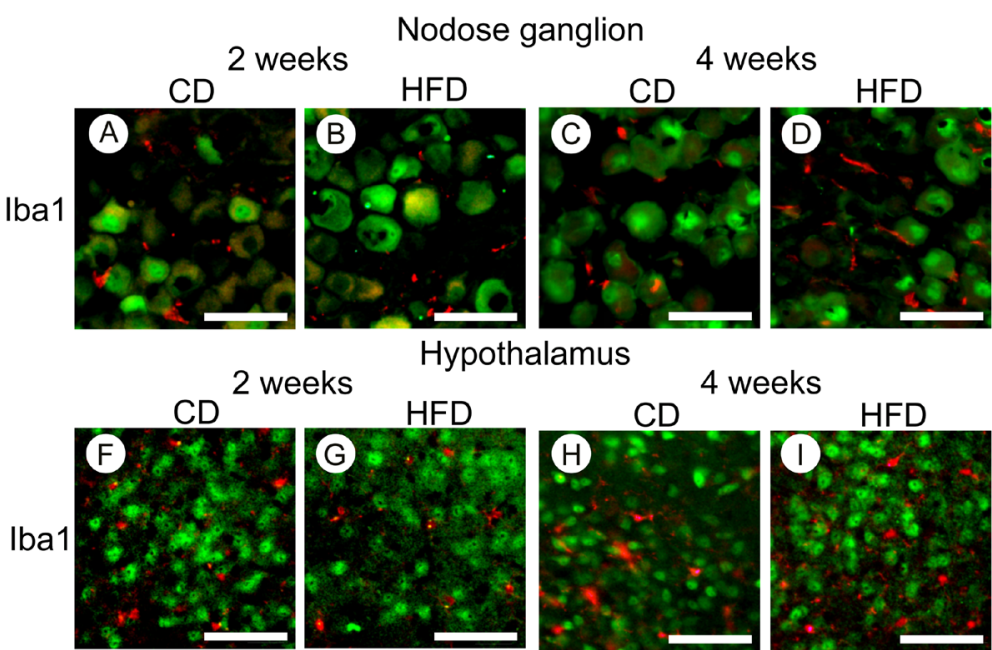

Hypothalamus
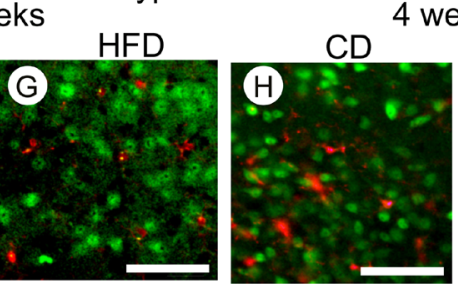

HFD
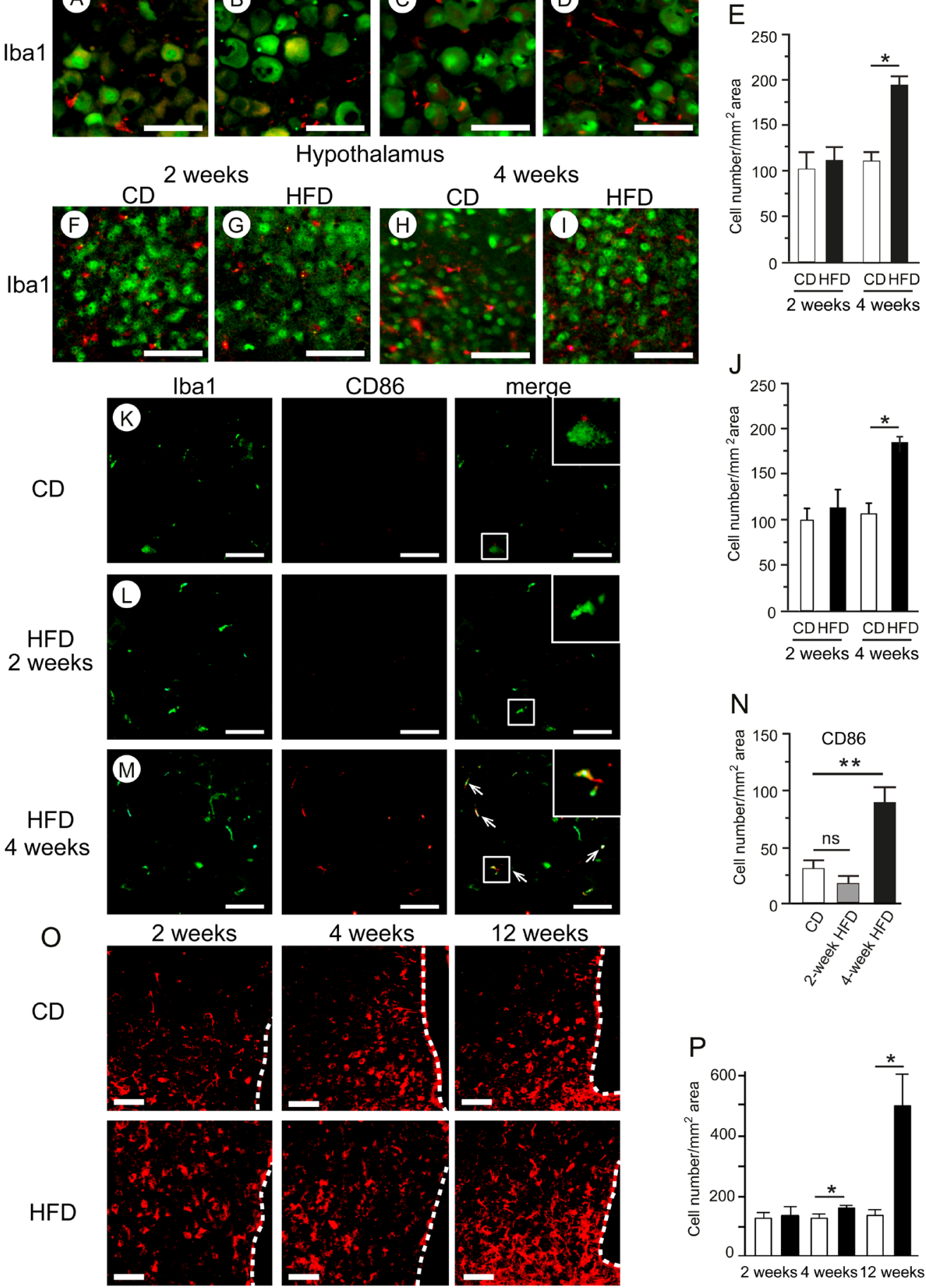

Figure 5

HFD-induced macrophage accumulation in the nodose ganglion and hypothalamus. Representative immunohistochemical detections of Iba1 (red) and NeuN (green) in the nodose ganglion (A, B, C and D) and hypothalamus (F, G, H and I) of 2- or 4-week CD- or HFD-fed mice. Numbers of cells stained with anti-Iba1 antibody in the nodose ganglion (E) and hypothalamus (J). Representative images of Iba1 (green) and CD86 (red) in the nodose ganglion ( $K$, L and M) of 2- or 4-week CD- or HFD-fed mice. Arrows indicate co-localization of CD86 with lba1. Numbers of CD86-positive cells in the nodose ganglion (N). Histochemical analyses of HSP72 in the hypothalamus of 2-, 4- or 12-week HFD-fed mice (O). Numbers of HSP72-positive cells in the hypothalamus $(P)$. Values are means \pm s.E.M. $n=4-5 . * P<0.05, * * P<0.01$ vs CD. Scale bars, $50 \mu \mathrm{m}$. Dotted lines indicate the third ventricle. http://jme.endocrinology-journals.org
https://doi.org/10.1530/JME-17-0192
() 2018 The authors Published by Bioscientifica Ltd. Printed in Great Britain

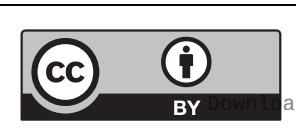

This work is licensed under a Creative Commons Attribution 3.0 Unported License. 
A

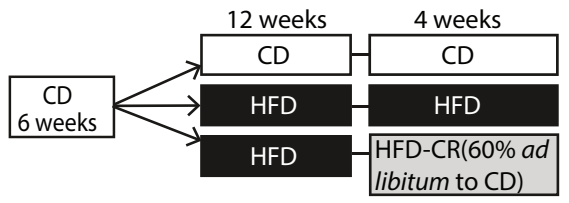

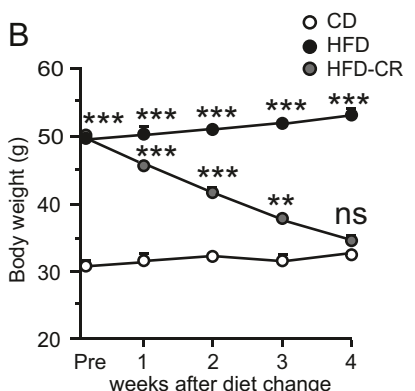

G
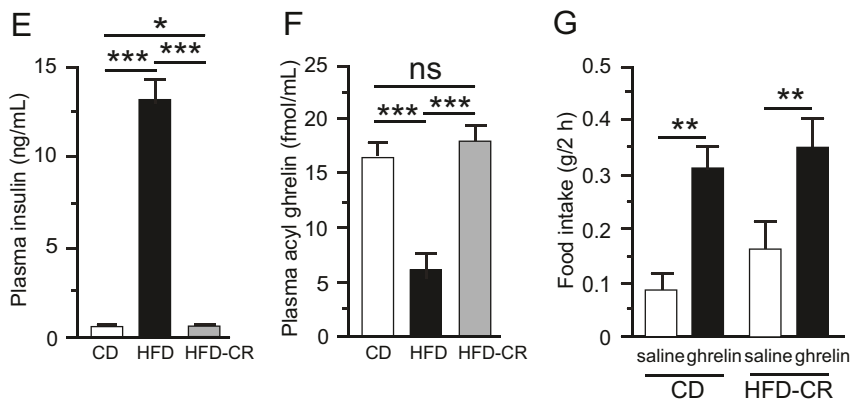

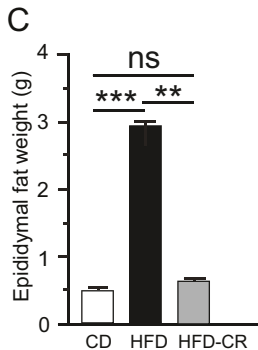

$\mathrm{H}$ Nodose ganglion

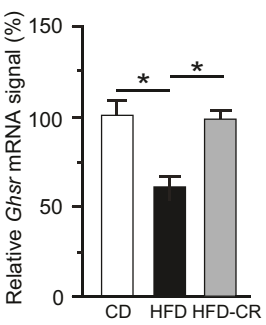

2 weeks
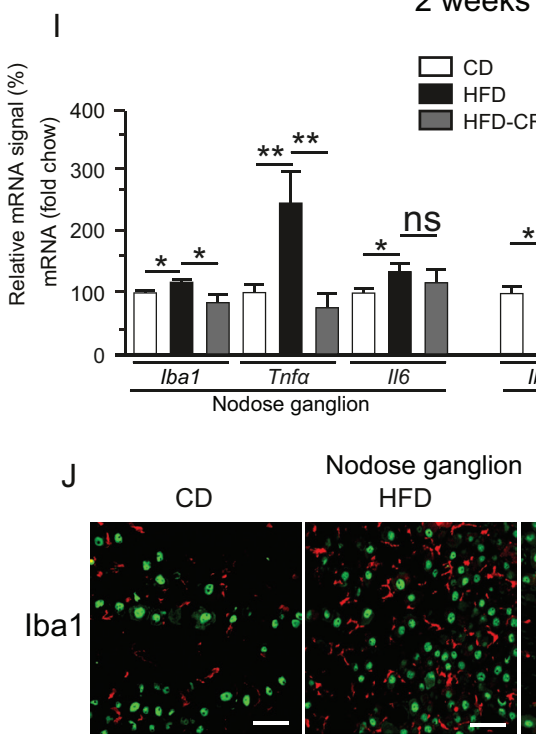

CD
HFD
HFD-CR

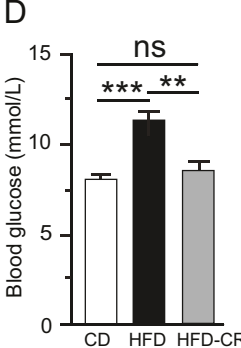

음
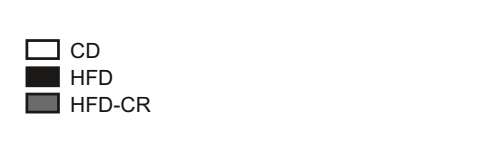

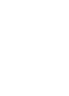

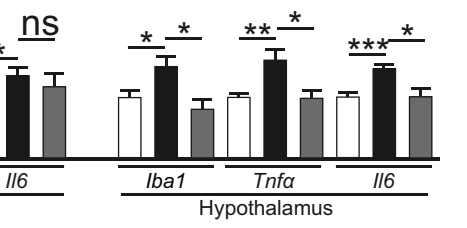

Nodose ganglion HFD

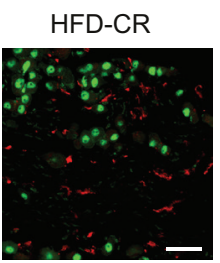

HFD-CR

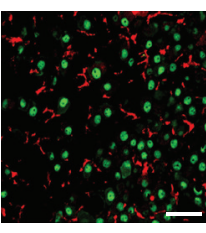

Hypothalamus HFD

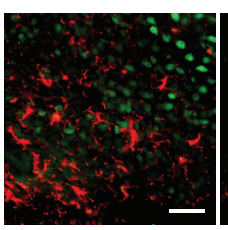

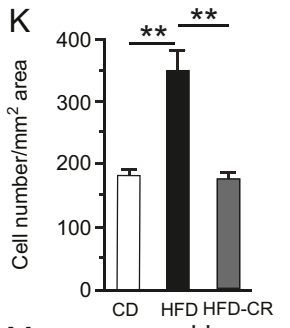

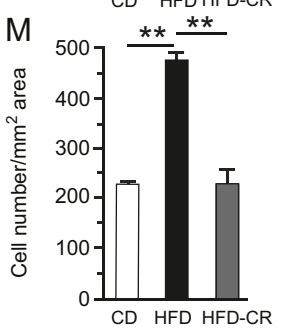

Figure 6

Schematic representation of caloric restriction experiment (A). Mice were initially placed on 12-week CD followed by 4 additional weeks of chow (CD), 12-week HFD followed by 4 additional weeks of HFD (HFD), or 12-week HFD followed by switching to chow and caloric restriction to $60 \%$ of ad libitum intake (HFD-CR). Body weight, epididymal fat weight, blood glucose, plasma insulin, and ghrelin levels of CD, HFD and HFD-CR mice (B, C, D, E and F). $* * P<0.01, * * * P<0.001$ vs CD in (B). $n=6-8$. Effect of diet change on ghrelin-induced food intake (G). mRNA expression of Ghsr (H) in the nodose ganglion. mRNA levels of $I b a 1, T n f \alpha$, and $I I-6$ in the nodose ganglion and hypothalamus of CD, HFD, or HFD-CR mice (I). $n=8-10$. Immunohistochemical detections of Iba1 (J), and numbers of cells stained with Iba1 antibody in the nodose ganglion in CD, HFD, and HFD-CR mice (K). $n=4$. Values are means \pm S.E.M. Iba1, red; NeuN, green. ${ }^{*} P<0.05, * * P<0.01, * * * P<0.001$ in (C) to (M). Scale bars, $50 \mu \mathrm{m}$.

http://jme.endocrinology-journals.org https://doi.org/10.1530/JME-17-0192
() 2018 The authors Published by Bioscientifica Ltd. Printed in Great Britain

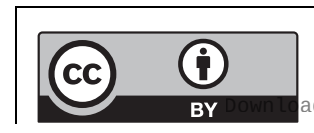

This work is licensed under a Creative Commons Attribution 3.0 Unported License. 
The average number of Iba1-positive macrophages in the nodose ganglion and hypothalamus was also significantly higher in the HFD group than that in both the CD and HFD-CD/CR groups, whereas no significant difference was observed between the $\mathrm{CD}$ and HFD-CD/CR groups (Fig. 6J, K, L and M).

\section{Discussion}

We investigated whether exposure to HFD could affect ghrelin responsiveness in mice. Metabolic inflammation in both the nodose ganglion and hypothalamic arcuate nucleus developed 2-4 weeks after the start of the HFD. The anabolic activities were also abolished during this interval. In a previous study, we found that 1-day HFD feeding in C57BL/6J mice induced inflammatory responses, concomitant with upregulation of activated macrophage/microglia markers and inflammatory cytokines, in the nodose ganglia and arcuate nuclei (Waise et al. 2015). Thaler and coworkers found that the HFD-induced inflammatory response in the rat hypothalamus exhibited a complex 'on-off-on' pattern in which the initial inflammatory response developed 3 days after the start of HFD (60\% energy from fat), followed by a decline to baseline from days 7 to 14 , and a subsequent return to elevated levels by day 28 (Thaler et al. 2012). This hypothalamic inflammatory response occurred rapidly, even before substantial weight gain, in response to HFD feeding. Microglia/macrophages play regulatory roles in the innate immune system of the nervous system by responding to pathological insults. Acute inflammatory cytokine production, which develops rapidly in response to HFD in animals, is crucial for the initiation of adaptive immune responses, and allows the host to adapt to pathological conditions (Thaler et al. 2012, Waise et al. 2015). Chronic inflammatory signals in the nodose ganglion and hypothalamus cause microglia/macrophages to assume a ramified morphology. In response to homeostatic perturbations, these more active cells produce cytokines, reactive oxygen species and other toxic mediators (Neumann et al. 2006, Hanani 2010). The time course of inflammatory responses observed in this study was well correlated with the development of ghrelin resistance at 4 weeks. Iba1, ionized calcium-binding adaptor molecule 1 , is a marker of microglia/macrophage activation in the nervous system (Ito et al. 1998). We found that 4-week HFD-induced activation of microglia/macrophages and inflammatory responses in the nodose ganglion and hypothalamus, as reflected by greater numbers of both Iba1- and CD86-positive macrophage/microglia. These cells were morphologically rounded and more ramified, indicating that more activated subtypes of macrophages/ microglia were present after 4 weeks of HFD. Lending support to this argument, expression of TLR4, a putative mediator of saturated fatty acid-induced inflammatory signaling, was elevated in the nodose ganglion after 4 weeks of HFD.

Berkseth and coworkers showed that 4-week CD (12\% energy from fat) following 16-week HFD (60\% energy from fat) in C57BL/6J mice reversed the activation of astrocytes and microglial accumulation in the hypothalamic arcuate nucleus (Berkseth et al. 2014). Another group demonstrated that calorie-restricted weight loss restored the ghrelin responsiveness of NPY/AgRP neurons (Briggs et al. 2013). In this study, the metabolic inflammation of HFD-fed mice was reversible when their body weight, fat mass and plasma glucose and insulin returned to normal levels after 4-week caloric restriction. Concomitantly, the orexigenic activity of ghrelin was restored, and plasma ghrelin and Ghsr expression in the nodose ganglion were also normalized. Ghsr expression is regulated by transcription factors including AP2, bHLH and NREBP, as well as hormones such as growth hormone, $\beta$-estradiol, triiodothyronine and hydrocortisone (Yin et al. 2014). mRNA levels of $A p 2 a$, Bhlhe22 and Nrebp in both the nodose ganglion and hypothalamus did not differ significantly between CD- and HFD-fed mice. It remains possible that unknown transcription factors of Ghsr are downregulated in nodose ganglion and hypothalamus of HFD mice, and the molecular mechanism by which Ghsr expression is reduced under HFD should be investigated in future research. Harvey and coworkers recently showed that the ghrelin/GOAT system regulates HFD-induced inflammation in the spleen and thymus (Harvey et al. 2017). In this study, we obtained no evidence of a direct interaction between ghrelin resistance and inflammation. However, the simultaneous development of ghrelin resistance and metabolic inflammation suggests a causal relationship between the two.

HSP72, a molecular chaperone, is expressed in multiple cell types, including neurons and glial cells. It protects stressed neurons from protein aggregation and apoptosis under various pathophysiological conditions (Foster \& Brown 1997, Waise et al. 2015). HSP72 downregulates expression of TNF $\alpha$, JNK and IKK, thereby alleviating metabolic dysregulation in obesity-induced insulin resistance (Henstridge et al. 2014). In this study, http://jme.endocrinology-journals.org https://doi.org/10.1530/JME-17-0192
(C) 2018 The authors Published by Bioscientifica Ltd. Printed in Great Britain
This work is licensed under a Creative Commons Attribution 3.0 Unported License.

ded from Bioscientifica.com at 04/26/2023 02:10:16PM 
upregulation of HSP72 in the hypothalamus of HFD-fed mice may have helped to prevent irreversible neuron damage, allowing recovery of hypothalamic inflammation by caloric restriction.

This HFD-CD/CR experiment had some limitations. For calorie restriction study 12 weeks HFD switched to $60 \%$ ad libitum of the CD because their body weight did not decrease enough to match with CD-fed controls. And as these mice $60 \%$ ad libitum of the CD, there might be possible they eat this small amount of diet at once and be starved for long time during CR. This long-term starvation may change their metabolic status.

In conclusion, our data showed that inflammation and unresponsiveness to peripherally administered ghrelin occurred by 4 weeks of HFD feeding in C57BL/6J mice. This ghrelin resistance was reversible following reversal of the HFD-induced inflammation and obesity phenotype by caloric restriction. These findings suggest that diet-induced inflammation begets a state of ghrelin resistance and that downregulation of ghrelin biosynthesis and ghrelin resistance under HFD could prevent humans and animals from overeating. Ghrelin plays multifaceted roles in the regulation of growth hormone secretion, cell proliferation and differentiation, neuroprotection, mood, immunity and learning and memory (Muller et al. 2015). Future studies should investigate how disruption of ghrelin signaling in obesity influences multiple types of homeostatic regulation within the body.

\section{Declaration of interest}

The authors declare that there is no conflict of interest that could be perceived as prejudicing the impartiality of the research reported.

\section{Funding}

This work was supported in part by JSPS KAKENHI (No. 25293216, No. 16H05333) and A-MED CREST (No. JP17gm0610016) to M N.

\section{Author contribution statement}

$\mathrm{F} \mathrm{N}, \mathrm{Z} \mathrm{W}$, and T O performed the experiments; $\mathrm{F} \mathrm{N}, \mathrm{H} \mathrm{S}$ and $\mathrm{M} \mathrm{N}$ edited the manuscript; F N, H S and M N approved the final version of manuscript; $\mathrm{K}$ $\mathrm{T}$ and $\mathrm{M} \mathrm{N}$ conceived and designed the research; $\mathrm{F} \mathrm{N}$ analyzed the data; $\mathrm{F} \mathrm{N}, \mathrm{T} \mathrm{O}, \mathrm{H} \mathrm{S}$ and $\mathrm{M} \mathrm{N}$ interpreted the experimental results; $\mathrm{F} \mathrm{N}$ and $\mathrm{T} \mathrm{O}$ prepared the figures and $\mathrm{F} \mathrm{N}$ and $\mathrm{M} \mathrm{N}$ drafted the manuscript.

\section{Acknowledgments}

The authors thank Sumie Tajiri and Eiko Kurata (University of Miyazaki) for technical support.

\section{References}

Begg DP \& Woods SC 2013 The endocrinology of food intake. Nature Reviews Endocrinology 9 584-597. (https://doi.org/10.1038/ nrendo.2013.136)

Berkseth KE, Guyenet SJ, Melhorn SJ, Lee D, Thaler JP, Schur EA \& Schwartz MW 2014 Hypothalamic gliosis associated with high-fat diet feeding is reversible in mice: a combined immunohistochemical and magnetic resonance imaging study. Endocrinology $\mathbf{1 5 5}$ 2858-2867. (https://doi.org/10.1210/en.2014-1121)

Briggs DI, Enriori PJ, Lemus MB, Cowley MA \& Andrews ZB 2010 Dietinduced obesity causes ghrelin resistance in arcuate NPY/AgRP neurons. Endocrinology 151 4745-4755. (https://doi.org/10.1210/ en.2010-0556)

Briggs DI, Lockie SH, Benzler J, Wu Q, Stark R, Reichenbach A, Hoy AJ, Lemus MB, Coleman HA, Parkington HC, et al. 2014 Evidence that diet-induced hyperleptinemia, but not hypothalamic gliosis, causes ghrelin resistance in NPY/AgRP neurons of male mice. Endocrinology 155 2411-2422. (https://doi.org/10.1210/en.2013-1861)

Briggs DI, Lockie SH, Wu Q, Lemus MB, Stark R \& Andrews ZB 2013 Calorie-restricted weight loss reverses high-fat diet-induced ghrelin resistance, which contributes to rebound weight gain in a ghrelindependent manner. Endocrinology 154 709-717. (https://doi. org/10.1210/en.2012-1421)

Burdyga G, Varro A, Dimaline R, Thompson DG \& Dockray GJ 2006 Ghrelin receptors in rat and human nodose ganglia: putative role in regulating CB-1 and MCH receptor abundance. American Journal of Physiology-Gastrointestinal and Liver Physiology 290 G1289-G1297. (https://doi.org/10.1152/ajpgi.00543.2005)

Cummings DE \& Overduin J 2007 Gastrointestinal regulation of food intake. Journal of Clinical Investigation 117 13-23. (https://doi. org/10.1172/JCI30227)

Date Y, Murakami N, Toshinai K, Matsukura S, Niijima A, Matsuo H, Kangawa K \& Nakazato M 2002 The role of the gastric afferent vagal nerve in ghrelin-induced feeding and growth hormone secretion in rats. Gastroenterology 123 1120-1128. (https://doi.org/10.1053/ gast.2002.35954)

Date Y, Shimbara T, Koda S, Toshinai K, Ida T, Murakami N, Miyazato M, Kokame K, Ishizuka Y, Ishida Y, et al. 2006 Peripheral ghrelin transmits orexigenic signals through the noradrenergic pathway from the hindbrain to the hypothalamus. Cell Metabolism 4 323-331. (https://doi.org/10.1016/j.cmet.2006.09.004)

De Souza CT, Araujo EP, Bordin S, Ashimine R, Zollner RL, Boschero AC, Saad MJ \& Velloso LA 2005 Consumption of a fat-rich diet activates a proinflammatory response and induces insulin resistance in the hypothalamus. Endocrinology 146 4192-4199. (https://doi. org/10.1210/en.2004-1520)

Foster JA \& Brown IR 1997 Differential induction of heat shock mRNA in oligodendrocytes, microglia, and astrocytes following hyperthermia. Molecular Brain Research 45 207-218. (https://doi. org/10.1016/S0169-328X(96)00138-6)

Gardiner JV, Campbell D, Patterson M, Kent A, Ghatei MA, Bloom SR \& Bewick GA 2010 The hyperphagic effect of ghrelin is inhibited in mice by a diet high in fat. Gastroenterology 138 2468.e1-2476.e1. (https://doi.org/10.1053/j.gastro.2010.02.012)

Grabauskas G, Wu X, Lu Y, Heldsinger A, Song I, Zhou SY \& Owyang C 2015 KATP channels in the nodose ganglia mediate the orexigenic actions of ghrelin. Journal of Physiology 593 3973-3989. (https://doi. org/10.1113/JP270788)

Hanani M 2010 Satellite glial cells in sympathetic and parasympathetic ganglia: in search of function. Brain Research Reviews 64 304-327. (https://doi.org/10.1016/j.brainresrev.2010.04.009)

Hardie DG 2004 The AMP-activated protein kinase pathway--new players upstream and downstream. Journal of Cell Science $\mathbf{1 1 7}$ 5479-5487. (https://doi.org/10.1242/jcs.01540) http://jme.endocrinology-journals.org https://doi.org/10.1530/JME-17-0192
(C) 2018 The authors Published by Bioscientifica Ltd. Printed in Great Britain

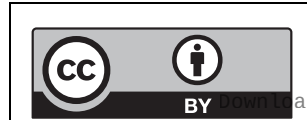

This work is licensed under a Creative Common Attribution 3.0 Unported License. 
Harvey RE, Howard VG, Lemus MB, Jois T, Andrews ZB \& Sleeman MW 2017 The ghrelin/GOAT system regulates obesity-induced inflammation in male mice. Endocrinology 158 2179-2189. (https:// doi.org/10.1210/en.2016-1832)

Henstridge DC, Whitham M \& Febbraio MA 2014 Chaperoning to the metabolic party: the emerging therapeutic role of heat-shock proteins in obesity and type 2 diabetes. Molecular Metabolism 3 781-793. (https://doi.org/10.1016/j.molmet.2014.08.003)

Hotamisligil GS 2017 Inflammation, metaflammation and immunometabolic disorders. Nature 542 177-185. (https://doi. org/10.1038/nature21363)

Ito D, Imai Y, Ohsawa K, Nakajima K, Fukuuchi Y \& Kohsaka S 1998 Microglia-specific localisation of a novel calcium binding protein, Iba1. Molecular Brain Research 57 1-9. (https://doi.org/10.1016/S0169328X(98)00040-0)

Kohno D, Gao HZ, Muroya S, Kikuyama S \& Yada T 2003 Ghrelin directly interacts with neuropeptide-Y-containing neurons in the rat arcuate nucleus: $\mathrm{Ca} 2+$ signaling via protein kinase $\mathrm{A}$ and $\mathrm{N}$-type channel-dependent mechanisms and cross-talk with leptin and orexin. Diabetes 52 948-956. (https://doi.org/10.2337/ diabetes.52.4.948)

Moehlecke M, Canani LH, Silva LOJe, Trindade MRM, Friedman R \& Leitão CB 2016 Determinants of body weight regulation in humans. Archives of Endocrinology and Metabolism 60 152-162. (https://doi. org/10.1590/2359-3997000000129)

Morton GJ, Cummings DE, Baskin DG, Barsh GS \& Schwartz MW 2006 Central nervous system control of food intake and body weight. Nature 443 289-295. (https://doi.org/10.1038/nature05026)

Muller TD, Nogueiras R, Andermann ML, Andrews ZB, Anker SD, Argente J, Batterham RL, Benoit SC, Bowers CY, Broglio F, et al. 2015 Ghrelin. Molecular Metabolism 4 437-460. (https://doi.org/10.1016/j. molmet.2015.03.005)

Nakazato M, Murakami N, Date Y, Kojima M, Matsuo H, Kangawa K \& Matsukura S 2001 A role for ghrelin in the central regulation of feeding. Nature 409 194-198. (https://doi.org/10.1038/35051587)

Naznin F, Toshinai K, Waise TMZ, NamKoong C, Md Moin AS, Sakoda H \& Nakazato M 2015 Diet-induced obesity causes peripheral and central ghrelin resistance by promoting inflammation. Journal of Endocrinology 226 81-92. (https://doi.org/10.1530/JOE-15-0139)
Neumann J, Gunzer M, Gutzeit HO, Ullrich O, Reymann KG \& Dinkel K 2006 Microglia provide neuroprotection after ischemia. FASEB Journal 20 714-716. (https://doi.org/10.1096/fj.05-4882fje)

Perreault M, Istrate N, Wang L, Nichols AJ, Tozzo E \& StrickerKrongrad A 2004 Resistance to the orexigenic effect of ghrelin in dietary-induced obesity in mice: reversal upon weight loss. International Journal of Obesity and Related Metabolic Disorders 28 879-885. (https://doi.org/10.1038/sj.ijo.0802640)

Reed DR, Bachmanov AA \& Tordoff MG 2007 Forty mouse strain survey of body composition. Physiology and Behavior 91 593-600. (https:// doi.org/10.1016/j.physbeh.2007.03.026)

Schaeffer M, Langlet F, Lafont C, Molino F, Hodson DJ, Roux T, Lamarque L, Verdie P, Bourrier E, Dehouck B, et al. 2013 Rapid sensing of circulating ghrelin by hypothalamic appetite-modifying neurons. PNAS 110 1512-1517. (https://doi.org/10.1073/ pnas.1212137110)

Schenk S, Saberi M \& Olefsky JM 2008 Insulin sensitivity: modulation by nutrients and inflammation. Journal of Clinical Investigation $\mathbf{1 1 8}$ 2992-3002. (https://doi.org/10.1172/JCI34260)

Thaler JP, Yi CX, Schur EA, Guyenet SJ, Hwang BH, Dietrich MO, Zhao X, Sarruf DA, Izgur V, Maravilla KR, et al. 2012 Obesity is associated with hypothalamic injury in rodents and humans. Journal of Clinical Investigation 122 153-162. (https://doi.org/10.1172/ JCI59660)

Tschöp M, Smiley DL \& Heiman ML 2000 Ghrelin induces adiposity in rodents. Nature 407 908-913. (https://doi.org/10.1038/35038090)

Waise TMZ, Toshinai K, Naznin F, NamKoong C, Md Moin AS, Sakoda H \& Nakazato M 2015 One-day high-fat diet induces inflammation in the nodose ganglion and hypothalamus of mice. Biochemical and Biophysical Research Communications 464 1157-1162. (https://doi. org/10.1016/j.bbrc.2015.07.097)

Yin Y, Li Y \& Zhang W 2014 The growth hormone secretagogue receptor: its intracellular signaling and regulation. International Journal of Molecular Sciences 15 4837-4855. (https://doi.org/10.3390/ ijms15034837)

Zarbin MA, Wamsley JK, Innis RB \& Kuhar MJ 1981 Cholecystokinin receptors: presence and axonal flow in the rat vagus nerve. Life Sciences 29 697-705. (https://doi.org/10.1016/00243205(81)90022-9)

Received in final form 1 December 2017

Accepted 12 December 2017

Accepted Preprint published online 12 December 2017
This work is licensed under a Creative Common Attribution 3.0 Unported License. 